\title{
The phonological mistake and 5D paradigm
}

In the first part of this article I present a background in scientific studies on dyslexia, from cognitive science to the neuropedagogical perspective. In this investigation the analysis of mental processes is the most important thanks to comparison with genetic research. In the second part, the dyslexic condition is seen from the perspective of the neuro-motor approach, named the Praxic Motor Theory, which improves neural circuits and inter-hemispherical exchange, electrical transmission and evoked potentials. In this perspective, the dyslexia condition is a disorder related to lack of coordination, including disorganization in space-time and lateral dominance. The phonological hy- pothesis referring to a lack of sign-sound association in dyslexia is inappropriate, as the term phonology has been intended in English literature as a more complex process and not simply an association between phoneme and grapheme. It is related to access to the word, groups of sounds, rather than single sounds. In this sense the dyslexic reader does not make a phonological mistake in terms of association, but a kinetic-motor one, in space-time from left to right.

\section{KEY WORDS}

phonetics; phonology; praxic motor paradigm; praxic motor theory

ORGANIZATION - Department of Education, Cultural Heritage and Tourism, University of Macerata, Macerata, Italy aUthors' Contributions - A: Study design - B: Data collection - C: Statistical analysis · D: Data interpretation .

E: Manuscript preparation · F: Literature search · G: Funds collection

CORRESPONDING AUthor - Prof. Piero Crispiani, Department of Education, Cultural Heritage and Tourism, University

of Macerata, Piazzale Luigi Bertelli - 62100 Macerata, Italy, e-mail: pierocrispiani@gmail.com

to CITE thIS ARTICLE - Crispiani, P. (2016). The phonological mistake and 5D paradigm. Health Psychology Report, 4(1), 1-7.

doi: 10.5114/hpr.2016.56606

RECEIVED 24.08.2015 · REVIEWED 05.10.2015 · ACCEPTED 18.11.2015 · PUBLISHED 31.12.2015 


\section{BACKGROUND}

Important theories on dyslexia and its related disorders have found a scientific cohesive platform in the cognitive science domain towards which different knowledge converges. This includes all behavioural sciences, with particular reference to the forms with a view of the mind in a neurophysiological, neuropsychological, neuropedagogical perspective. Mental processes and behaviours are currently interpreted within neuroscience (which has been developing intensively) and genetics paradigm.

Today, theoretical assumptions and good practices about dyslexia stem from different contexts and approaches.

\section{IN THE BILDUNG}

A series of reflections, which can approximately be dated to around the year 2000, have led to the surfacing not only of conceptual frameworks which have shaped new visions of the phenomenon called dyslexia but also, as a whole and observed in perspective, have established new theoretical guidelines and experiences, a whole bildung related to this matter. We would like to point out some of the most inclusive developments:

1. The progressive increase of work related to neurophysiological analysis of neural circuits, the neural network, inter-hemispherical exchanges, electric transmission and evoked potentials.

2. In-depth genetic research with particular attention to the phenomena of chromosome deletion, a research field which on one hand gives an account of very familiar disorders and of the dyslexic and dyspraxic person and on the other gives important options open to a possible united or intersected nature of several disorders related to genetic errors, as for example the fragile $\mathrm{X}$ syndrome.

3. A better way of dealing with the syndromic picture, meaning a careful and prolonged observation of symptoms, their description and classification (in our case in special semiotic maps) without which the investigation of the dyslexic phenomenon, like any behavioural disorder, would appear inadequate.

4. A more targeted extension of the analysis of reading and writing and mathematical skills disorders, as well as the methods, to adolescents and adults.

5. A process of partial revision of terminology and definitions in this area and the overcoming of the tendency to triviality ${ }^{1}$ or to ambiguity as in the case of terms such as deficit / disorder, phone / phoneme, phonological / phonetic learning / enforceability, etc.

6. A reasoned comparison of syndromes, process analysis and interpretation of symptoms. Fertile cognitive contributions derive from a comparison between disorders / diseases or between these and normality, a practice that has produced interesting contributions about other conditions such as autism, the fragile X syndrome, ADHD, etc.

The latter can be considered the highest scientific achievement since it corresponds to the versatile or multicomponent nature of reading and writing skills. Today we advocate inter- and transdisciplinary approach; this, however, has been suggested before (multifactoriality, connectionism / modularism).

Reductive or exclusively etiological approaches, especially in Italy, have delayed taking charge of the dyslexic phenomenon, due more to corporate reasons rather than scientific ones, whereas the international debate appears more open to critics and to a direct and situational observation of the behaviour and difficulties of the dyslexic person.

It is after all the right adjustment to the working styles typical of behavioural sciences which follow a natural process concentrating essentially on: - observation,

- description,

- comparison,

- classification,

- analysis and research,

- interpretation / explanation,

- theorizing / suggestions,

- monitoring.

\section{IN THE DIAGNOSTIC PROCESS}

The increased awareness of the complexity of the phenomenon and of the theoretical outlines, together with the affirmation of common sense, allows us to reconsider the nature and the aims of the diagnostic process (declarative diagnosis + functional diagnosis) according to at least three statements we currently agree on:

1. The observation and description of the dyslexic condition indicators are close to the most direct observers, the people who are in contact with dyslexics and their behaviour on a daily basis. That includes parents, teachers and educators in which we recognize the primary source.

2 . The fundamental conceptual and lexical distinction proposed by The International Classification of Functioning, Disability and Health (ICF; of the World Health Organization, 2005) between structures and functions (the foundational paradigm of clinical pedagogy) and between learning the function and practising the function, with an essential nosographic distinction between:

- learning to read (d 140) and reading (d 166),

- learning to write (d 145) and writing (d 170),

- learning to calculate (d 150) and calculating (d 172). 
The conceptual option is very important as it interprets the recognition of dyslexia as a disorder of the executive functions, and puts aside the more common learning disorder term.

3. Diagnostic practices are redefined by DSM-5 (The Diagnostic and Statistical Manual of Mental Disorders) (APA, 2013) in a more ecological and clinical way, using assumptions that totally change intelligence psychometric practices. In fact the metric value of intelligence is no longer mentioned but diagnostic procedures are used. They consider:

a. inadequacy of a single source of data;

b. necessary synthesis of:

- medical, development, education and family history of the subject,

- past and present learning difficulties,

- impact on operating at school, work and in social life,

- past and present school reports,

- activities that require school activities,

- evaluations based on the curriculum,

- "past or current scores obtained in individual tests standardized on school performance".

DSM-5 manual itself talks about clinical evaluations supported by appropriate procedures "If an intellectual, sensorial, neurological or motor disorder is suspected". "Therefore, the overall assessment will engage professionals experienced in the field of specific learning disorder and psychological / cognitive evaluation".

\section{INTO CURRENT VIEWS}

Research, when compared, and the resulting theoretical developments, which we have mainly taken from that paradigmatic shift phase that can be placed around the beginning of our century, give us more credible or, anyway, attracting more attention etiological principles. We will make a distinction emphasizing that they bear many conceptual and lexical similarities, witnessing a theoretical evolution which we can today identify in the sense of the complex neuro-biological nature of the disorder and with reference to executive / procedural functions.

1. The Visual-Motor Theories (Wolff, Cohen, \& Drake, 1984) anchored to the observation of critical situations caused by crowding and by the pace of executive performance which is requested, thus linked to movement and to space-time organization, aspects which are often neglected in Italy.

2. The Cerebellar Theory (Nicholson \& Fawcett, 1995; Nicholson, Fawcett, \& Dean, 2001) and Procedural Learning Theory Deficit by R. Nicholson and A. Fawcett (2011; Nicolson, Fawcett, Brookes, \& Needle, 2010).

3. The Magnocellular Theory by John Stein et al. (Stein \& Walsh, 1997; Stein, 2001a,b).
4. The Neurological and Neurodynamic Theories (Parisi, 1999; Chiarenza, 1998; Chiarenza, Di Pietro, \& Casarotto, 2014).

5. Theories centred on integration: visual-auditory-motor functions by Marta Bogdanowicz (2000).

6. The Neuro-psychomotor Theories, of which some extraordinary examples can be found among researchers since the 1930s (Orton, 1937), consolidated in the great period of psychomotricity especially in France and Italy, up to today's Praxic Motor Theory (Crispiani \& Capparucci, 2009; Crispiani, 2012; Crispiani \& Palmieri, 2015).

\section{THE PHONOLOGICAL MISTAKE}

Within the phonological mistake approach dyslexia is interpreted in an etiological way, which results in many critical concepts and applications at schools.

Anglophone literature generally refers to the term of phonology / phonological as the use of sounds in its structural and functional indistinction; therefore the analysis of phones is called phonology.

In general linguistics and physiolinguistic speech therapy (neurological, pedagogical, psychological), two functions are distinguished conceptually and lexically. a. Phonetics is concerned with the pronunciation of phones in motor, articulatory and physical skills and can be affected by speech disorders such as dyslalia, dysphonia, dysarthria, or oral dyspraxia. It is an area of motricity, or kinetic language, whose treatment is speech therapy and/or educational.

b. Phonology is concerned with giving a meaning to phones in a semantic or mental way and can be affected by errors in understanding or sign-sound or sound-sign association errors. It is an area of linguistics, or semantics, whose treatment is speech therapy and/or educational but which carries at least two further meanings:

- The Phonological Mistake is a symbolic mistake, related to the symbolic function, of neuropsychological dynamics relating to allocation of meaning to objects, gestures, sounds, etc.;

- The Phonological / symbolic Mistake is extremely rare and occurs either as failure in recognizing symbols or as slowness in the symbolic process which, in both cases, impedes or disrupts both speech and the reading and writing process...

The dyslexic person, child or adult, does not present the Phonological Mistake (Crispiani, 2012), in fact: 1. The majority of dyslexic errors, with the exception of substitutions, are of motor and space-time nature (slowness, interruptions, inversions, simplifications, loss of line when starting a new line, tiredness, etc.);

2. The Italian dyslexic person never makes mistakes when reading individual or isolated graphemes, except in the case of mirror letters such as p / b / d / q;
The phonological mistake and $5 D$ paradigm 
3. Substitution errors can happen when reading words;

4. The dyslexic person often reads well in the first lines of the text;

5. The number of errors diminishes when the dyslexic person reads keeping the paper in an oblique position;

6. The dyslexic person does not have problems of symbolic order in recognizing single graphemes, mathematical symbols, computer icons, mobile phone icons and symbols which surround us;

7. In the rare case of symbolic disorder, which occurs in all symbolic performances, the bad reading is a derived effect and does not constitute a specific disorder;

8. The phonological hypothesis relating to reading and understood as sign-sound association could make sense, in its rarity, in the Italian language because of its transparency, but not in opaque languages as the majority of the existing languages in which reading in fact is not trained as decoding of individual graphic signs into phones.

In the Italian language we can therefore observe both an improper use of the term phonological, which in the English language has a broader and more inclusive meaning of access to the word rather than to the single phone, and a conceptual error since a dyslexic reader does not make the Phonological Mistake but kinetic errors in space-time when scrolling horizontally and from left to right.

On this matter, in my opinion, a broad consensus of analysis in the scientific world of genetic and/or neurobiological research, some of which is authoritatively represented or quoted, is being built.

\section{THE NEUROBIOLOGICAL FOCUS}

We believe that the paradigmatic shift, placed around the year 2000, has been built on the decisive contribution of some research and studies concerned with the etiological and nosographic dimension of dyslexia and more precisely:

- a more accurate analysis of syndromic indicators;

- comparative analysis;

- genetic and neurobiological research.

These three areas are not hierarchically arranged since the analysis and the interpretation of symp-

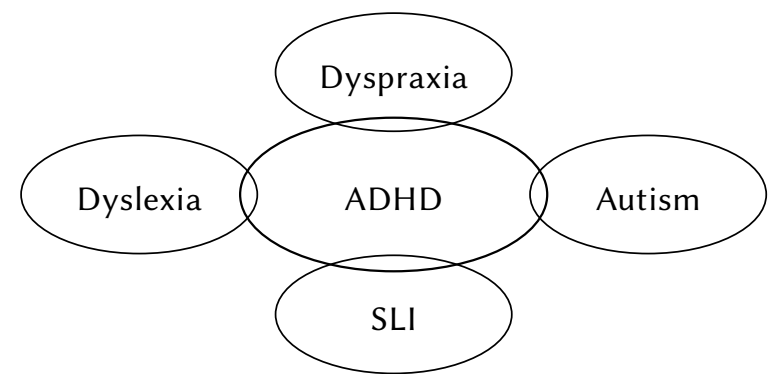

Figure 1. Comorbidity of neurodevelopmental disorders (Stein, 2015). toms are as important as genetic or neurological research although the two lines of action often remain separate as in the case of autism, the fragile X or other syndromes. In this regard I would like to give as an example our findings about speech delay in individuals with dyspraxia; the same assumptions were made in neurophysiological studies by Prof. Giuseppe Chiarenza (1998; Chiarenza \& Njiokiktjien, 2008).

However, referring to the neurobiological border some conceptual options are important:

- concentrating on cortical flows instead of physiologies restricted to a cerebral structure, a topic which has been perceived by theoreticians of the Neurological Association since the mid '90ties, of which Dr Antonio Parisi (1999) has been a witness;

- the detection of neuronal migration and related abnormalities on which the magnocellular theory is based;

- the dysfunctions of inter-hemispherical exchange to which today we often refer;

- language impairments related to cerebellar lesions (Fabbro, Moretti, \& Bava, 2000);

- the cerebellar dysfunctions and the resulting "procedural disorders";

- neurological disorganization as the human condition.

We are talking, however, of theoretical vectors which are not dissociated and are probably rather similar expressions of genetically ordered conditions and which, I believe, will be a field of interesting discussions in the coming years.

Many signs envisaging, in many ways, the idea of a functional disorder condition which affects many areas of human behaviour converge in this direction (Stanovich, 2000). We notice in fact a trend towards a recomposition process of syndromes in various ways:

- compaction of autism, ADHD, dyslexia associations which is taking place in Germany (see: Witruk, 2011);

- the increasing overlap in the readings of symptoms (Witruk, 2011);

- polarization around the institution of dyspraxia of which three examples which support this trend are given: John Stein (2015) reports on an assumption

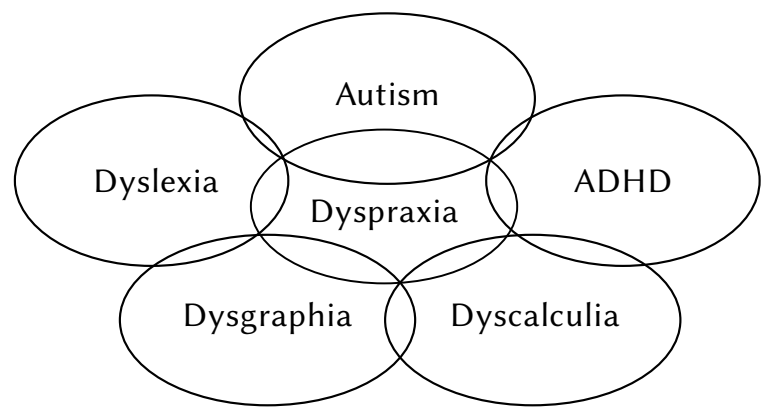

Figure 2. Polarization of dyspraxia (Tulukdar, 2012). 
anchored to ADHD (Figure 1); Afroza Tulukdar (2012) polarises on dyspraxia (Figure 2); Our position is included in dyspraxia and generates an ecological diagram (DIA-ECO) (Figure 3).

The current debate gives us then a number of considerations which are more credible:

- sense of the complexity of the dyslexic phenomenon and its "irreducibility";

- theoretical plurality;

- multicomponent / multifactorial concept;

- association with executive disorders;

- recovery of the motor and body aspect in general (Mounstephen, 2011);

- progressive acknowledgment of qualitative indicators such as confusion and mess;

- a trend towards comparative association to dyspraxia (Macintyre, 2000; Oliviero, 2001);

- genetic-constitutional nature of the disorder.

\section{THE 5D PARADIGM}

The theory we are putting forward has originated mainly from a number of analyses of the dyslexic-dyspraxic phenomenon and of the learning processes of reading and writing skills and mathematical skills, and from the fruitful comparison with the traditional views on the subject of neuro-motor and neuro-cognitive sciences. The Praxic Motor Theory recognizes dyslexia as a condition of disorder in the accomplishment of the fundamental coordinative functions with an influence on space-time organization and on the structure of lateral dominance.

The most reliable etiological pattern is concerned with neuronal disorganization which influences inter-hemispheric exchange and cortical circuits whose functioning is characterized by slowness, mess and randomization, which lead to disorderly execution of many functions, according to the $1^{\text {st }}$ TPM diagram:

\section{from \\ NEUROLOGICAL DISRUPTION \\ to \\ FUNCTIONAL or EXECUTIVE DISORDER}

Keeping focused on the neurological level, compared with the survey on dyspraxic behaviours, we can outline the $2^{\text {nd }}$ TPM diagram:

\section{GENETIC DEFECTS}

\section{ABNORMAL NEURONAL MIGRATIONS CEREBELLAR DYSFUNCTION \\ OR MAGNOCELLULAR THINNING}

\section{NEUROLOGICAL DISRUPTION}

\section{FUNCTIONAL DISORDER}

(executive, procedural, praxic, space-time, fluidity, fluency, sequential...)

\section{CALCULATION AND READING AND WRITING SKILL DISORDER}

\section{DISHARMONY OF DEVELOPMENT \\ (de Ajuriaguerra, 1974)}

The Praxic Motor Paradigm therefore shifts the conceptual axis from an indistinct linguistic problem (Crispiani, 2012) to a multifaceted motor problem which includes linguistic difficulties in the motor component, as in the case of:

- speech start hesitations;

- slowness or disfluency;

- pauses in speech;

- phonic and / or syllabic inversions;

- syntactic incoordination;

- sequential loss (active and passive);

- progressive tiredness.

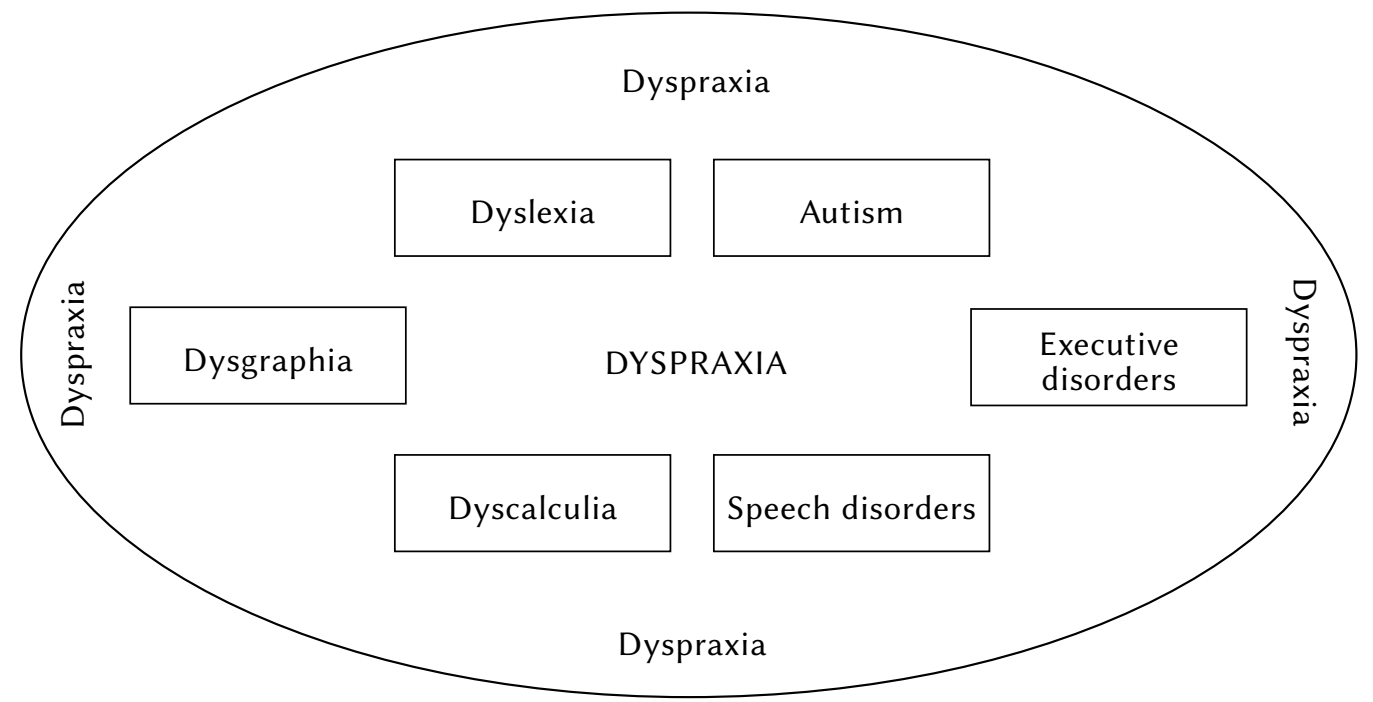

Figure 3. Ecological diagram of dyspraxia (Crispiani, 2012). 


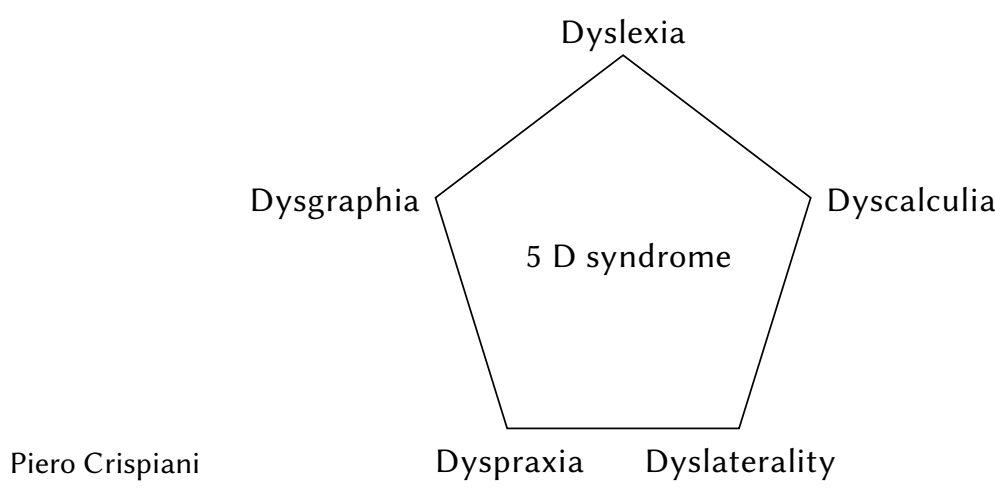

Figure 4. The 5D Paradigm by Piero Crispiani.

Syndromic traits which appear evident in the reading process as:

- speech start hesitations;

- slowness or disfluency;

- pauses;

- phonic and/or syllabic inversions;

- loss of line when starting a new line;

- additions or omissions;

- linking;

- cognitive loss;

- progressive tiredness.

It is useful to draw attention to writing manifestations, which prove more interesting, such as the writing of multiple-digit numbers, putting numbers in a column, oral calculation, composition of geometric shapes, etc., which clearly show their praxic-motor and space-time nature and are far from misleading phonological concepts.

We would like to point out here that we recognize the constant coexistence of five conditions with the prefix DIS, typical of a state of qualitative disorder in human behaviour, the 5D Paradigm (Figure 4).

In the light of this theoretical perspective, and having taken advantage of contributions drawn from important past authors but also from closer researchers such as Giuseppe Chiarenza and Antonio Parisi, Angela Fawcett and Marta Bogdanowicz, together with the many researchers and professionals of ITARD, it was possible to build theoretical guidelines and professional practices relating to prevention, diagnosis and functional assessment, educational and pedagogical organization, monitoring, educational and professional orientation, the care of environment and materials. These theoretical guidelines concentrate on cognitive optimization and on searching for authentic autonomy of the dyslexic person based on skills (functional autonomy) rather than on substitutes (subsidized autonomy).

\section{CONCLUSIONS}

Since the 1970s most of the research and theoretical developments related to dyslexia have focused on the "phonological problem" (see: Stanovich, 2000; Hatcher \& Snowling, 2002; Snowling \& Hulme, 2006).

In Italy the question was associated with errors in the translation from sign to sound or sound to sign, or the incorrect connection between phoneme and grapheme. In this sense Italian phonology relates exclusively to the assignment of meaning to the signs, and the reading grapheme is isolated within words (Crispiani, 2012).

In the English-speaking context the phonological phenomenon regards the more extensive provision of reading of words, or of their pronunciation, rather than the process of decoding or coding sign / sound, which, in fact, in the English language, being opaque, is not determined.

The English reader, in fact, does not decode individual signs but the entire string of groups or words, and therefore performs a lexical reading, predictive, not bound to single and successive graphemes (Tallal, Miller, \& Fitch, 1995).

The interpretation of many Italian authors has instead brought attention to a hypothetical problem of translation of individual signs into sounds (Crispiani, 2012), a phenomenon that would belong to a semantic process, just the symbolic function (symbolization), whose disorder (rare) kept to a severe disorder semantic / symbolic one.

The Italian dyslexic reader does not make any errors in the reading of individual graphemes, except in the case of mirror letters such as p, b, d, q, and may make words substitutions, in the direction from the left to the right?

The good Italian reader does not read making the fusion of individual graphemes but for predicting entire words (a global lexical strategy), as well as the readers in opaque languages do. Reading making the fusion between letters, step by step, sub-lexical (noise-syllabic) is a pathological reading or non-reading, not a "model of reading": there is no "dual channel".

The fallacy of the dyslexic who cannot see or does not translate correctly the letters generated a misleading solution (read a pile of letters, large letters, slowly, etc.), but also the idea of a constitutional inability to read.

Dyslexia is related (dysgraphia) to a functional disorder and slip forwards, from left to right, according to a space-time commitment and coordinated. Concepts that we found in many authors since the beginning of the century (Orton, 1937; MucchielliBourcier, 2004; Jadoulle, 1962; Cacciaguerra, 1969 etc.) justify the theory of dyslexia as a disorder of the praxic-motor functions, an interpretation based on and close to the major neurophysiological and neurogenetic international theories (Cerebellar Theory, Magnocellular Theory, etc.).

\section{ENDNOTES}

1 Banality, indistinct use, overlapping. 


\section{REFERENCES}

American Psychiatric Association. (2013). Diagnostic and Statistical Manual of Mental Disorders ( $5^{\text {th }}$ ed.). Washington, DC: Authors.

Bogdanowicz, M. (2000). Integracja percepcyjno-motoryczna. Teoria - diagnoza - terapia [Integration of visual-auditory-motor functions. Theory diagnosis - therapy]. Warszawa: CMPP-P.

Cacciaguerra, F. (1969). Direzionalità e difficoltà motorio-fonetica nella dislessia [Directionality and motor-phonetic difficulties in dyslexia]. Acta Medica Auxologia, 1, 256-266.

Chiarenza, G., \& Njiokiktjien, C. (2008). Le disprassie dello sviluppo e i disturbi motori associati [Developmental Dispraxia and its related motor disorders]. Amsterdam: Suyi Publications.

Chiarenza, G. (1998). Aspetti neurofisiologici dell'Apprendimento. Le difficoltà di apprendere [Neurophysiological aspects of learning. Learning difficulties]. Torino.

Chiarenza, G., Di Pietro, S., \& Casarotto, S. (2014). The psychophysiology of reading. International Journal of Psychophysiology, 94, 111-119.

Crispiani, P., \& Capparucci, M. L. (2009). Dislessia, disprassia e motricità [Dyslexia, dyspraxia and motricity]. Psicomotricità, 13, 41-46.

Crispiani, P., \& Palmieri, E. (2015). Improving the fluidity of whole word reading with a dynamic co-ordinated movement approach. Asia Pacific Journal of Developmental Differences, 2, 158-183. doi: $10.3850 / \mathrm{S} 2345734115000277$

Crispiani, P. (2012). Dislessia come disprassia sequenziale [Dyslexia as sequential dyspraxia]. Parma: Junior-Spaggiari.

de Ajuriaguerra, J. (1974). Manuel de Psychiatrie de l'Enfant [Child Psychiatry Manual]. Milano: Masson.

Fabbro, F., Moretti, R., \& Bava, A. (2000). Language impairments in patients with cerebellar lesions. Journal of Neurolinguistics, 13, 173-188.

Hatcher, J., \& Snowling, M. J. (2002). The phonological representations hypothesis of dyslexia from theory to practice. In: G. Reid \& J. Wearmouth (eds.), Dyslexia and literacy. Theory and practice (pp. 69-83). Chichester: John Wiley \& Sons Ltd.

Jadoulle, A. (1962). Apprentissage de la lecutre et dyslexie [Learning to read and dyslexia]. Presses Universitaires de France.

Macintyre, C. (2000). Dyspraxia in the early years: Identifying and supporting children with movement difficulties. London: David Fulton.

Mounstephen, M. (2011). How to detect developmental delay and what to do next. London and Philadelphia: Jessica Kingsley Publishers.

Mucchielli-Bourcier, A. (2004). La prévention de la dyslexie à l'école [Preventing dyslexia at school]. Paris: L'harmattan.
Nicholson, R. L., \& Fawcett, A. J. (1995). Dyslexia is more than a phonological disability. Dyslexia, 1, 19-36.

Nicholson, R. L., \& Fawcett, A. J. (2010). Dyslexia, learning, and the brain. Cambridge and London: The MIT Press.

Nicholson, R. L., Fawcett, A. J., \& Dean, P. (2001). Dyslexia, development and the cerebellum. Trends Neuroscience, 24, 515-516.

Nicolson, R. I., Fawcett, A. J., Brookes, R. L., \& Needle, J. (2010). Procedural learning and dyslexia. Dyslexia, 16, 194-212. doi: 10.1002/dys.408

Nicolson, R. I., \& Fawcett, A. J. (2011). Dyslexia, dysgraphia, procedural learning and the cerebellum. Cortex, 47, 117-127. doi: 10.1016/j.cortex.2009.08.016

Oliviero, A. (2001). Motricità, linguaggio e apprendimento [Motricity, language and learning]. Scuola e Città, 1, 6-18.

Orton, S. (1937). Reading, writing and speech problems in children: A presentation of certain types of disorders in the development of the language faculty. New York: W. W. Norton.

Parisi, A. (1999). I bambini dallo sguardo sfuggente [Children who do not look you in the eye]. Edizioni Scientifiche Italiane.

Snowling, M. J., \& Hulme, C. (2006). Language skills, learning to read and reading intervention. London Review of Education, 4, 63-76.

Stanovich, K. E. (2000). Progress in understanding reading: Scientific foundations and new frontiers. New York: Guilford Press.

Stein, J., \& Walsh, V. (1997). To see but not to read. The magnocellular theory of dyslexia. Trends in Neuroscience, 20, 147-152.

Stein, J. (2001a). The sensory basis of reading problems. Developmental Neuropsychology, 20, 509534. doi: 10.1207/S15326942DN2002_4

Stein, J. (2001b). The magnocellular theory of developmental dyslexia. Dyslexia, 7, 12-36.

Stein, J. (2015, April). Visual dyslexia and its treatment. In: J. Stein (chair), Wobbles, Warbles and Fish - The Neurology of Dyslexia. Seminar conducted at the meeting of Malta Dyslexia Association, Malta.

Tallal, S., Miller, S., \& Fitch, H. (1995). Neurobiological basis of speech: A case for the pre-eminence of temporal processing. The Irish Journal of Psychology, 16, 194-219.

Tulukdar, A. (2012). Dyspraxia/DCS. Teacher's Pocketbook. Hampshire: Laurel House.

Witruk, E. (2011). Overview of assessment and treatment methods for dyslexia - with special reference to alternative methods. Ad Verba Liberorum, 3, 4-18.

Wolff, P. H., Cohen, C., \& Drake, C. (1984). Impaired motor timing control in specific reading retardation. Neuropsychologia, 22, 587-600.
The phonological mistake and 5D paradigm 